\title{
Laboreal
}

Volume $4 \mathrm{~N}^{\circ} 1$ | 2008

Ergologia, trabalho, desenvolvimentos

\section{Revisitar a actividade humana para colocar as questões do desenvolvimento : projecto de uma sinergia franco-lusófona}

Revisitar la actividad humana para colocar las cuestiones del desarrollo: proyecto de una sinergia franco-lusa Revisiter l'activité humaine pour poser les questions du développement : projet d'une synergie franco-lusophone Re-visit human activity to pose the questions of development : project of a french-speaking-portuguese-speeking cooperation

Yves Schwartz, Rufi Adriano e Fyad Abderrahmane

\section{(2) OpenEdition}

\section{Edição electrónica}

URL: http://journals.openedition.org/laboreal/12192

DOI: $10.4000 /$ laboreal. 12192

ISSN: 1646-5237

\section{Editora}

Universidade do Porto

\section{Refêrencia eletrónica}

Yves Schwartz, Rufi Adriano e Fyad Abderrahmane, "Revisitar a actividade humana para colocar as questões do desenvolvimento : projecto de uma sinergia franco-lusófona », Laboreal [Online], Volume 4 $\mathrm{N}^{0} 1$ | 2008, posto online no dia 01 julho 2008, consultado o 18 outubro 2019. URL : http:// journals.openedition.org/laboreal/12192; DOI : 10.4000/laboreal.12192

Este documento foi criado de forma automática no dia 18 outubro 2019.

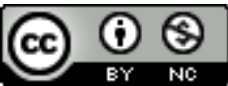

Laboreal está licenciado com uma Licença Creative Commons - Atribuição-NãoComercial 4.0 Internacional. 


\title{
Revisitar a actividade humana para colocar as questões do desenvolvimento : projecto de uma sinergia franco-lusófona
}

\author{
Revisitar la actividad humana para colocar las cuestiones del desarrollo: \\ proyecto de una sinergia franco-lusa \\ Revisiter l'activité humaine pour poser les questions du développement : projet \\ d'une synergie franco-lusophone \\ Re-visit human activity to pose the questions of development : project of a \\ french-speaking-portuguese-speeking cooperation
}

Yves Schwartz, Rufi Adriano e Fyad Abderrahmane

O projecto apresentado neste número de Laboreal tem a sua origem nas jornadas que decorreram em Maputo, capital de Moçambique, no mês de Junho de 2007. Estas jornadas tinham como objectivo lançar as bases de uma Rede FrancoLusófona, destinada a trazer uma nova contribuição às questões do desenvolvimento (local). Nestas jornadas, reuniram-se e trabalharam conjuntamente os seguintes parceiros : do lado lusófono, Marianne Lacomblez e Liliana Cunha (respectivamente, Professora e doutoranda na Faculdade de Psicologia e de Ciências da Educação da Universidade de Porto), Eliza Echternacht (Professora no Departamento de Engenharia de Produção na Universidade Federal de Minas Gerais, em Belo Horizonte), Rufino Adriano (docente de filosofia na Universidade São Tomás de Maputo e doutorando da Université de Provence); e do lado francófono, Abderhamane Fyad, Professor na Faculdade de Medicina d'Oran, Abdallah Nouroudine, docente na Universidade de Comores, em Moroni, Yves Schwartz, Professor e director científico do Departamento de ergologiaAPST da Université de Provence, em Aix-en-Provence. Pareceu interessante 
aos responsáveis da revista dar uma visibilidade editorial, não tanto ao conteúdo dessas jornadas, mas :

- às convicções intelectuais partilhadas, que estiveram na base das convergências entre os diferentes parceiros.

- e assim às inflexões teóricas e às perspectivas concretas que avançaram sobre as questões do desenvolvimento.

2 Contudo, trata-se apenas de um princípio, e este dossier poderá constituir um estímulo para o alargamento desta iniciativa. Porém, a combinação entre uma diversidade cultural linguística, geográfica e das sinergias operatórias em projecto, a partir desses pressupostos largamente partilhados contribuem de maneira original para tratar de duas questões actualmente tão debatidas: de um lado, o problema do(s) desenvolvimento(s) local(is) num planeta marcado por grandes disparidades, e de outro lado, a necessidade de passarmos a colocar a questão desses desenvolvimentos, com uma preocupação de coerência à escala planetária (o que o conceito de "desenvolvimento sustentável" e todas as suas ambiguidades e as questões ambientais e de aquecimento climático indicam).

\section{Revisitar a "actividade", repensar o conceito de trabalho}

3 Se nos interrogarmos sobre a cristalização dessas convergências, logo nos daríamos conta de que ela não surge de maneira espontânea, mas sim de uma herança, a saber : a corrente ergonómica, que se consolidou à volta de Alain Wisner. Pela via da questão das transferências de tecnologia, Alain Wisner, falecido em 2003, apaixonou-se pelas questões do desenvolvimento planetário, com o olho aguçado sobre o que, actualmente, se costuma designar, após ele, uma ergonomia da actividade. Postura que desperta uma extrema atenção às heranças, culturas e patrimónios locais investidos em todas as situações de trabalho. Todos os parceiros presentes neste dossier são, de uma forma ou de outra, devedores desta abordagem aprofundada do trabalho humano. Portanto, a presença desta herança comum, neste dossier, não é puramente casual: a tese que defendemos aqui é que não se pode tratar dos problemas de desenvolvimento sem prestar uma atenção renovada ao que chamamos de actividade humana, assim como ao trabalho humano [1] que é, na verdade, uma das suas formas essenciais e estratégicas. Voltando a Alain Wisner: antes de desenvolver o que designou por "Antropotecnologia" (1997), o seu ensino tinha como centro de gravidade o seu diagnóstico sobre situações de trabalho europeias marcadas pelo governo tayloriano nas grandes organizações industriais. São os princípios da organização científica do trabalho, no começo de um declínio após os acontecimentos de 1968, na Europa, que lhe permitiram melhor formular esta distinção, prometida para um futuro alargado (ambígua como todas as grandes fórmulas) entre o trabalho dito "prescrito", antecipado, aos mínimos detalhes, pelos serviços de métodos, e o trabalho dito "real", a ser redescoberto de cada vez, "à lupa", em cada posto de trabalho - apesar de ter sido prédefinido de forma rígida por essas prescrições. Se se generalizar este ensinamento para além dessas condições históricas iniciais, quer isto dizer que não se conhece plenamente a actividade industriosa humana à distância das circunstâncias concretas que se tem que gerir aqui e agora. Ou para usar uma expressão mais "ergológica" ninguém pode dogmatizar sobre o agir industrioso dos seus semelhantes unicamente 
em desaderência relativamente a este. Acabamos de mencionar aqui o termo "ergológico" : a démarche ergológica - no sentido etimológico do estudo da actividade humana -, desenvolveu-se nos primórdios dos anos 1980, principalmente na Université de Provence. A referência wisneriana [ $\left.{ }^{2}\right]$ teve grande importância, nomeadamente, pela focalização do conceito de actividade, ponto de partida de todas as elaborações conceptuais e dispositivos operacionais actualmente em uso. Démarche progressivamente sancionada pela criação de um Departamento específico, na Universidade, criando diplomas profissionais nacionais; mais tarde, de mestrado em "ergologia", duplamente direccionado para as profissões, bem como para a investigação. Durante este percurso ela foi progressivamente enriquecida por colaborações científicas, por projectos cooperativos de diversas disciplinas em França e no estrangeiro. Dimensão internacional, por enquanto com tendência franco-lusófona como o revela este dossier. Assim, desde o final dos anos 1990, a construção desta démarche inscreve-se numa dinâmica colectiva "policêntrica". As diferentes contribuições deste dossier, bem como o glossário apresentado, permitirão aos leitores que não tiveram oportunidade de adquirir a cultura desta démarche de ter uma ideia do seu conteúdo, das diversas formas de apropriação e de interpretação de que pode ser objecto e do seu modo de articulação com os campos e as competências disciplinares existentes. A frase pela qual acabamos de comentar o horizonte da generalização dos ensinamentos wisnerianos - os riscos da dogmatização industriosa em "desaderência" poderia desaguar directamente na abordagem dos problemas do "desenvolvimento", que nos reuniu. A antropotecnologia de Alain Wisner percebeu precocemente esta dimensão planetária económico-cultural. Mas, se o nosso dispositivo ergológico, à semelhança de muitos herdeiros desta ergonomia da actividade, se cristalizou à partida sobre as formas as mais correntes de trabalho nos nossos países europeus, trabalho em plena transformação, a distinção wisneriana entre trabalho prescrito e trabalho real permitiu, de facto, re-estudar com um olhar infinitamente mais exigente e mais preparado para encontrar complexidades inéditas. Nós focalizámo-nos, em consequência, durante muitos anos, sobre esta forma de trabalho que podemos designar por trabalho stricto sensu (sem aí ver nenhum privilégio de qualidade) e que poderíamos definir como uma prestação remunerada numa sociedade mercantil e de direito. Focalização legítima, num universo de questões muito vasto : desde logo porque a actividade industriosa humana não poderia jamais ser correctamente antecipada por nenhum modelo teórico antecipativo, sabendo que é necessário aprender o trabalho com os que o praticam, se quisermos ser um actor respeitoso dos projectos de transformação deste trabalho. Múltiplas interrogações sobre "o que é trabalhar" surgem, então, interpelando todo o tipo de disciplinas. A título de exemplo, nas ciências da linguagem : como pensar nas relações entre o trabalho e a linguagem (falar do trabalho, no trabalho, a propósito do trabalho)? No âmbito das psicologias, das neurociências, como é que o trabalho se incorpora na pessoa e no corpo humano? Como é que se codifica um contrato de trabalho, como definimos o não-trabalho, no âmbito jurídico e político ? E, por fim, questões colocadas à filosofia : o que é fabricar um conceito a propósito do trabalho e acerca do trabalho ? Todas essas questões nunca deixaram de preocupar, com especificidades e diferenças, aqueles para quem a reconsideração dos princípios de governação tayloriana pareceu um desafio essencial para o pensamento, assim como para a vida social. Em resumo, não seria cega a abordagem da actividade humana de trabalho construída em descrições, diagnósticos, preconizações que dão prioridade à postura em desaderência ? Este foi o ponto crucial 
da démarche ergológica do trabalho, que desagua num certo regime de produção de saberes denominado, a partir de 1994, por "dispositivos dinâmicos a três pólos" [3]. Caminhando, apareceu a alguns que limitar-se ao trabalho stricto sensu acabava por avançar, nas reflexões sobre o trabalho, para uma trajectória demasiado estreita. No respeitante ao "dispositivo ergológico" tem sido decisiva a presença de estudantes com outras culturas de trabalho, de outros problemas e perspectivas de transformação, cuja importância ao nível dos desequilíbrios mundiais não poderia escapar-nos. Tomemos como exemplo o caso da nossa colaboração intelectual com Abdallah Nouroudine, nosso parceiro durante mais de 10 anos na nossa aventura colectiva. Estudante comoriano, doutorado em filosofia, na sequência de um estudo notável sobre a questão da "modernização" da pesca nos Comores (caso de referência em matéria de transferência de tecnologia, cf. Nouroudine, 2001), incitou-nos com outros a experimentar os conceitos ergológicos neste campo que designámos desde há algumas décadas a questão do Desenvolvimento. A sua contribuição neste dossier acaba por demonstrá-lo. Porquê esta necessidade de alargar? Não há nenhuma razão para considerar o trabalho stricto sensu como uma espécie de forma "canónica" do trabalho para a humanidade. A análise de toda a actividade industriosa humana baseada neste pressuposto, avaliando as proximidades e as distâncias em relação a esta forma de prestação supostamente privilegiada, acabaria por negligenciar elementos de inteligibilidade essenciais para toda e qualquer dinâmica de transformação do estado actual das coisas. Sem sombra de dúvidas, estamos diante do inconveniente do conceito de "trabalho informal", que ao designar um continente da produção da vida social sobre o planeta [4], acaba por ser definido negativamente e unicamente como o contrário do trabalho stricto sensu. Compreendemos, a razão pela qual este tratamento reducionista do trabalho informal poderá ser uma ofensa aos olhos dos nossos colegas provenientes de países que designámos de "países em desenvolvimento" e que não se encontram neste olhar redutor posto sobre uma dimensão fundamental do seu tecido social. o projecto de investigação de Abderhamane Fyad, confrontado frequentemente na sua prática médica com este trabalho informal, propõe repensar de maneira crítica esta designação de "informal" e o texto "O trabalho informal : um objecto ergológico ?" apresenta os seus motivos [5]. De facto, quando vivemos em países com uma forte "taxa" de "informalidade" - e é o caso de Moçambique, mas também em graus variados da Argélia e Brasil -, percebemos imediatamente que, por um lado, a noção de "informal" se torna ambígua e confusa, e por outro lado, percebemos que o trabalho "não stricto sensu" pode revelar muito mais aspectos reais de toda actividade de trabalho, incluindo o stricto sensu. No entanto, a pluridimensionalidade da actividade de trabalho, no trabalho "não stricto sensu" remete-nos ao estudo de Abdallah Nouroudine sobre a "mobilização da mão-de-obra" onde é nomeadamente questão, à escala de uma aldeia comoriana, a "profunda imbricação entre o trabalho mercantil e o trabalho não mercantil" e "a mescla das dimensões de trabalho e da vida" (Nouroudine, 2003, p 177-178). Esta dimensão foi novamente tratada no seu texto do presente dossier. No entanto, dessas questões emergem: podemos pensar nos problemas do desenvolvimento sem medir essas "transgressões", as "extensões" do conceito de trabalho? Podemos pensar que esta mescla em plena visibilidade no caso do trabalho "não stricto sensu" estaria completamente ausente nas formas stricto sensu do trabalho ? Ora, vejamos : através da questão do trabalho "não stricto sensu" acabamos por chegar a um ponto de similitude entre Moçambique e Comores, por um lado, e Argélia e Brasil, por outro lado. Tais similitudes existem, mas também é importante não 
neutralizar as suas diferenças. São esses paralelismos e essas diferenças que enriquecem o trabalho colectivo. No tocante ao Brasil : parece-nos que o Brasil escapa a categorizações simplistas no que diz respeito à problemática do desenvolvimento. Sem dúvida podemos falar de um lugar determinado na divisão internacional de trabalho em relação ao que os nossos amigos brasileiros designam de "países centrais"; mas, trata-se apenas de uma situação em plena evolução, e notámo-lo cada vez mais com o Brasil que aparece como um futuro "grande" deste mundo e que nenhuma categorização simples pode caracterizar, o que afinal acaba por ser interessante já que evita o recurso a conceptualizações demasiado fáceis e de convenção [ $\left.{ }^{6}\right]$. Eliza Echternacht mostra como é que o Brasil no que concerne às patologias afectando o mundo do trabalho associa uma epidemiologia própria "aos antigos modos de adoecimento" a formas mais modernas, mais psicossomáticas, particularmente difundidas nas actividades ditas "de serviço". Do ponto de vista do desenvolvimento, tal como no Brasil, a Argélia, não cabe em nenhuma categoria simplista e estável. A Argélia tem simultaneamente, de um lado, importantes recursos económicos, que limitam fortemente no seu caso a pertinência do conceito de troca desigual, mas apresenta também uma elevada taxa de "informalidade", no que diz respeito ao trabalho, comparável neste plano com o caso do Brasil.

\section{Questionar o "desenvolvimento", uma ética de ofício em jogo}

Porque nos associamos para interrogar em conjunto o conceito de desenvolvimento ?

5 Sem dúvida, porque nos colocamos colectivamente questões como estas :

- Poderíamos, como psicólogos, ergónomos, juristas, economistas, médicos, filósofos, etc. pretender produzir conhecimentos sobre as actividades humanas, sobre as sociedades e o trabalho humano, sem nos instruirmos continuamente desta diversidade que acabamos de referir e que se renova incessantemente? Diversidade antropológica, económica, sociopolítica, enraizada nas diferentes histórias dos povos do planeta ? Sem termos em conta estes aspectos, que nível de generalização podemos dar aos conceitos que nós empregamos, em primeiro lugar, ao conceito de trabalho? Seríamos capazes na nossa actividade profissional como produtores e difusores de conhecimentos de antecipar, sem esta instrução, o que esta diversidade nos poderia levar a reconsiderar?

- Poderíamos leccionar as nossas diferentes disciplinas descrevendo apenas o estado actual da vida social no planeta,sem demonstrarmos preocupação em transformá-la ? Como sendo um estado de facto que não coexistiria com múltiplos possíveis diferentes ? No entanto, se temos a obrigação deontológica de assumir essas convocatórias para pensar outros possíveis nas configurações do presente, as configurações industriosas não estarão no epicentro da actual conjuntura? Como pensar essas transformações potenciais sem questionar eventuais reservas de alternativas que aí são assumidas e que são primitivamente "estrangeiras" aos nossos recursos e horizontes conceptuais de universitários?

- Outro modo de exprimir esta mesma preocupação deontológica : como compreenderíamos a história humana, da vida em sociedade, as nossas relações aos valores e às normas sociais, se as relações entre grupos humanos, sociedades, nações fossem parcialmente diferentes do que são hoje? Relações marcadas pelos desenvolvimentos e trocas desiguais, mistas de direito e de violências, de honestidade e de corrupção, de poderes, mas também de alterações graves dos meios ecológicos em amplo sentido? 
6

Neste plano, a questão colocada por Marianne Lacomblez torna-se preponderante e legítima: novas dimensões e novas feições se apresentam no contexto laboral, desde que as profissões passam a tornar-se femininas. Potencialidade primeiramente "silenciosa", como o é a "vigilância" de que fala, mas susceptível de levantar diferentemente as questões da vida, do trabalho, da vida social e logo do desenvolvimento. Como todas as reservas de alternativas sustentadas pelo trabalho, essa "vigilância" é discreta e, ao mesmo tempo, de peso decisivo. O que seria da vida industriosa se as questões, as renormalizações definidas tendencialmente [ $\left.{ }^{7}\right]$ pelas mulheres, acabassem por avançar no seu caminho ? Esta dimensão transversal, mesmo se muito variada, quase nunca nos parece colocada em questão. Podemos reflectir sobre as práticas de micro-crédito para as quais as mulheres parecem ter manifestado uma habilidade singular em se apropriar e que é susceptível de redefinir de forma nova as trajectórias possíveis dos desenvolvimentos [ $\left.{ }^{[}\right]$. Como desempenharíamos o nosso papel de académicos, de maneira diferente? Uma ética do ofício encoraja-nos nesta empreitada, através de uma Rede para podermos levar ao debate os nossos conhecimentos, das práticas e dos valores, portanto o nosso contributo com o objectivo de saber melhor como desempenhar o nosso ofício [].

\section{Alguns problemas clássicos do Desenvolvimento}

7 Estamos perfeitamente conscientes da amplitude da bibliografia $\left[{ }^{10}\right]$ já disponível sobre o tema. Estamos igualmente conscientes da necessidade de nos instruirmos junto das instituições que trabalham nestes temas há já muito tempo e nomeadamente "no terreno" (em França, pensamos por exemplo no INRA, Institut National de la Recherche Agronomique ; ou no IRD, Institut de Recherche sur le Développement). Mas desde que encaramos este campo com um olhar crítico, deparámo-nos com :

- constatações

- formulações

- pontos de dificuldades a desenvolver, a re-avaliar, a ter em conta de modo crítico [ $\left.{ }^{11}\right]$.

8 Na medida em que África é em particular objecto destes questionamentos, por um lado, e por outro lado, dado o facto de três dos seis autores deste dossier serem provenientes deste continente, relembremos antes de tudo algumas constatações, informações credíveis emitidas por organismos internacionais, que se encontram à nossa disposição :

- Metade da população Africana vive abaixo do nível de pobreza (Fundo Monetário Internacional FMI) ;

- Cerca de 2/3 da população é rural (agricultura, pastorícia) (Treillet, 2002, p. 16).

- 0 fosso da produtividade agrária entre a agricultura Subsahariana e a agricultura do Norte está na ordem de 1 para 500 ou 1000 (Treillet, 2002, p. 16). Não somos capazes de referir aqui como foram calculados estes ratios e qual o valor que se lhes atribui.

- 90 \% da população com acesso aos serviços de Internet localiza-se essencialmente na África do Sul.

9 Câmbios, transferências, ajudas : que instituições estão em jogo ? Existem organizações financeiras internacionais como o Banco Mundial (BM), e o FMI. Ao longo dos anos 1970/1980, houve iniciativas internacionais que favoreciam o papel central dos Estados africanos, aos quais sucederam os Planos de Ajustamento Estrutural (P.A.S.) 
sustentando, ao contrário, o mercado e o sector privado. Face a diversos fracassos ou dificuldades desses sistemas de ajuda foi lançado em 2001 o NEPAD (New Partenership for African Development) que se propõe a procurar uma relação mais equilibrada entre o Estado e o Mercado, um reforço às instituições, às organizações da sociedade civil e à autonomia do Estado na luta contra a corrupção e contra o privilégio dado aos interesses privados. A dependência face aos capitais externos mantém-se importante (Treillet, 2002, p. 18 e seq). As "Estratégias de Crescimento e Redução da Pobreza (SCRP), também têm como ambição superar o que fizeram os P.A.S. Sobre a análise desses programas reenviamos ao contributo de Abdallah Nouroudine.

Evidentemente, estão presentes no terreno algumas organizações mundiais como à FAO, OMS, ... Ao lado dos organismos e ferramentas internacionais existem organismos comunitários transnacionais dotados de políticas próprias em matéria de cooperação com países "emergentes", como: a Comunidade Europeia, os chamados Estados "desenvolvidos" que agem no terreno e em seu nome, as trocas internas à África (ver o papel das potências continentais como a África do Sul ou a Argélia), e as trocas ÁfricaÁsia em pleno desenvolvimento (a China, por exemplo) ou ainda com a América Latina (exemplo dos acordos de cooperação firmados entre o Brasil e Moçambique). A isto agrega-se uma multiplicação de Organizações Não Governamentais (ONG) de naturezas diversas cujo impacto local é considerável. Em suma, o peso da ajuda externa para África pode variar entre 1/5 e do desempenho nacional (caso de Moçambique, nos anos 90).

11 Uma tal heterogeneidade nessas interacções torna difícil a realização de diagnósticos ou balanços ; ao mesmo tempo, esses fluxos financeiros, de meios humanos e técnicos, levantam múltiplos questionamentos. Um país africano possui, simultaneamente, parcerias com outros países no ângulo bilateral, com organismos internacionais, com ONG's específicas de um Estado, ou trans-nacionais, ou confessionais... No entanto, esses parceiros externos podem lidar directamente com os Estados Africanos, mas também podem lidar directamente com as populações em áreas geográficas variáveis, com interlocutores institucionais os mais diversos, até mesmo incluindo os responsáveis comunitários das regiões rurais.

No âmbito desses fluxos às vezes massivos e desta miscelânea de actores institucionais de um lado e de outro, apresentam-se constantemente as seguintes questões :

- 0 risco da des-responsabilização dos parceiros locais, considerando os dispositivos de ajuda como um dado estabilizado.

- A questão da governação local, com as suas formas de redistribuição de ajudas.

- A própria concepção de ajuda externa. As questões levantadas ao financiamento externo: Será necessária uma ajuda financeira cujo controlo no uso escapa totalmente aos financiadores ? O apoio directo em termos de investimentos técnicos de grande dimensão, mas que podem ser sobredimensionados ou inadaptados às possibilidades locais de utilização, de manutenção, em relação aos desequilíbrios geográficos internos do país beneficiário [12] ? Ou da ajuda para os projectos locais concretos mas que supõem uma "ingerência admitida" do país hospedeiro para a sua implementação e monitorização [ ${ }^{[3]}$.

Estimamos que inúmeras orientações, dificuldades, contradições se podem encontrar num tal terreno. 
Estados? Estes são frequentemente apontados a dedo, criticados (daí a orientação “anti-Estado" dos P.A.S). É evidente que os Estados, em África, não se inscrevem na mesma história cultural de longa duração, não se incorporam nas mesmas consciências dos indivíduos e grupos como, por exemplo, é o caso dos Estados europeus. No entanto, são necessários para qualquer projecto de "desenvolvimento" : eles são indispensáveis para o fornecimento de infraestruturas, tanto na produção agrícola como na industrial, para garantir a protecção social, médica e para a educação. Portanto, podemos chegar aos seguintes paradoxos: se os dados fornecidos forem exactos (ver o Le Monde, 4/06/07) apenas $4 \%$ do capital da Mozal (maior produtor de alumínio em Maputo) é propriedade do Estado Moçambicano, 1 \% dos resultados anuais (10 milhões de dólares) financiam projectos locais. Contudo, os custos das infra-estruturas ligadas à implantação da Mozal (estradas, escolas, hospitais, etc.) dependentes do orçamento moçambicano não param de aumentar.

Estas constatações, estes conceitos apresentam mais questões do que respostas para a resolução dos mesmos. A situação actual não pode satisfazer-nos e reenviamos aqui para o ponto 2. Mas, de facto, quais são os objectivos, as estratégias a adoptar para contribuir para uma transformação ? "Crescimento", "Desenvolvimento" : talvez, mas de quem ? Definidos por quem ? Através de que critérios ? Que avaliações [ $\left.{ }^{14}\right]$ ? Quais as competências exigidas? Podemos dar a volta a essas questões que, de facto, podem ser definidas "em valor", recorrendo a indicadores universais e quantitativos, como ainda definir o crescimento unicamente através das evoluções do PIB ? É necessário, por exemplo, ter em atenção o facto de que não parece existir uma relação clara entre a redução da pobreza e a redução das desigualdades. O "território", a mobilidade, são parâmetros passivos que têm que ser quantificados em termos de "maximização de oportunidades económicas", através de uma linguagem estritamente económica ? A contribuição muito original de Liliana Cunha confronta-se com a quantificação exclusiva que neutraliza a significação "em valor" de noções ligadas ao conjunto do 
viver social. Estas questões não são novas, mas foram sim reformuladas recorrendo a conceitos como o de "desenvolvimento durável e sustentável", até mesmo invocando teorias actuais designadas de "decrescimento [15]". Portanto, como devemos tratar estes problemas de desenvolvimento e de maneira a não deslocar as dificuldades e criar novas?

\section{Não pensar "desenvolvimento" sem se instruir sobre as actividades de trabalho, os seus recursos, as suas potencialidades, as suas reservas de alternativas}

Diversos estudos antropológicos sobre o desenvolvimento destacam a articulação exógena/endógena, sobretudo quando se trata de disposição para inovar. Esta articulação e esta disposição sempre existiram na história humana. 0 interesse é de saber em que circunstâncias se produzem, de forma a que o "desenvolvimento" não seja decretado como tal unicamente do ponto de vista exógeno. Um tema bastante recorrente relativo ao melhoramento das práticas culturais é a "arborização" ou a florestação. Em que condições esta prática suscitada pelo exterior pode ser "inovadora", no sentido que acabamos de precisar? Questão levantada por Nicole Sibelet, investigadora do INRA, na sua tese (1995), sobre "a inovação em meio rural ou a capacidade de os actores locais inovarem na presença de intervenientes externos". Trata-se do estudo da "arborização" em Anjouan, uma das ilhas do arquipélago dos Comores. Em relação ao papel próprio aos serviços exógenos destacados para favorecer o desenvolvimento deste território, chegou à conclusão seguinte: "colocar os camponeses em posição de adopção de uma estratégia ofensiva, favorável à inovação, recorrendo ao reservatório das práticas locais eventualmente valorizadas por certos contributos exógenos ideologicamente aceitáveis (p. 226-227)". Abdallah Nouroudine evoca novamente esta questão a propósito do que ele chama, no seu texto, de "o esquecimento do trabalho", no Documento da Estratégia de Redução da Pobreza aplicado nos Comores : a arborização teve resultados desiguais, de acordo com cada região de sua aplicação: "não há incidência mecânica entre a introdução de uma técnica e a integração (apropriação) dessa técnica. O que se fará do trabalho real (a actividade) acabará por determinar o resultado : apropriação ou rejeição" [ $\left.{ }^{16}\right]$.

Em relação às inovações ou transferências de tecnologias, o que é que está em jogo nesta relação exógena/endógena? o que é que pode ser fonte de dificuldade? Certamente, não se trata de uma simples "resistência à mudança" [17]. Mas, tratase de uma questão de valores, de escolha de vida, veiculando saberes, competências mais ou menos incorporadas. Conjunto a tomar como positivo, o que não significa considerar como absoluto e intangível.

Das "opções de vida", é provavelmente neste ponto que a perspectiva de trabalho ergológica pode contribuir para o enriquecimento ou reposicionamento dos problemas de inovação e de desenvolvimento : o que sustenta esta perspectiva é que desde o agir infinitamente pequeno, toda a actividade (de trabalho) é sempre já debate de normas. Debate de normas entre as normas "antecedentes" (que o trabalho "prescrito dos ergónomos", pode ilustrar parcialmente) e as tendências a "re-normalizar" parcialmente as primeiras, tendo em conta as necessidades para cada ser singular de 
"viver" a situação (de trabalho) nas suas dimensões singulares, impossíveis de antecipar ou estandardizar $\left[{ }^{18}\right]$.

21 Porém, todo o debate só se resolve em função de valores e que revelam opções de vida à escala macroscópica. Liliana Cunha não deixa de relacionar a questão da mobilidade, nos dois casos que refere, com os "projectos", as "opções" de desenvolvimento da vida dos cidadãos e dos habitantes. A mobilidade inscreve-se nas "opções de melhoria das condições de vida" que não podem ser pressupostas à distância das populações que têm que viver e fazer viver esses espaços. Este é o preço a pagar pelo equilíbrio entre os serviços públicos e as prestações de privados. E, nesta perspectiva, a consideração do "uso de si por si" dos próprios prestadores de serviços, os motoristas, torna-se preciosa : "nas suas tentativas de conciliar objectivos diferentes", pelas suas estratégias profissionais quotidianas, eles encontram as "lógicas" em jogo e assim as escolhas de vida no seio das quais os diferentes protagonistas integram o valor mobilidade. Abdallah Nouroudine generaliza esta convicção ergológica: "pela análise das actividades humanas podemos fazer um esboço dos recursos e obstáculos que gera uma determinada situação de vida, numa perspectiva de desenvolvimento não visando negar as culturas produzidas pelos colectivos humanos, mas antes procurar e imaginar as modalidades da sua inscrição nas transformações necessárias à melhoria das condições de vida" (2006, p. 8-9). Qualquer questão tocante à actividade (produtiva, industriosa), por um lado, mobiliza saberes aderentes às suas formas de eficiência o que designamos de "re-normalização" - trata-se para ela da competência que permite concretizar essas renormalizações; por outro lado, este tratamento das renormalizações só tem sentido face a um mundo de valores. Assim, nenhum povo, nenhum juiz, nenhuma lógica métrica integrada numa calculadora, dispõe de uma escala de valores única para avaliar a qualidade, a hierarquia desses valores.

Neste plano e particularmente na história dos povos africanos, levantam-se questões de regulações mercantis e/ou estatais :

- Como pensar as inovações, as "ajudas ao desenvolvimento" em termos essencialmente quantitativos e de performances mercantis onde a distinção mercantil/não mercantil não se inscreve nitidamente nos valores do viver em conjunto, como vimos anteriormente?

- Como pensar uma centralização e uma redistribuição estatais dos recursos e das ajudas onde as comunidades familiares, das aldeias, étnicas, fazem a gestão de uma parte dos meios de subsistência, a sua repartição e assumem as arbitragens $\left[{ }^{19}\right]$ ?

Imaginemos a partir destes dados, os conflitos parciais de valores na reconstrução dessas regulações. É neste sentido onde o trabalho "não stricto sensu" (dito "informal") deve ser reconsiderado na sua eventual e parcial positividade em valor (cf. texto de Abderhamane Fyad). É aí que emerge a questão da "corrupção", que também tem que se deslocar (sem no entanto desaparecer).

24 A recusa de tomar em consideração esses valores de vida colectiva provoca uma incapacidade a identificar, tornar visíveis os saberes, saberes-fazer, que sustentam esses valores de vida e, diríamos, vice-versa. Podemos partir destes valores, para chegar às competências aderentes, ou partir dessas competências para tornar visíveis os valores que requerem. Sem este trabalho corremos o risco de definir "à cega" políticas de desenvolvimento e, caso fracassem, explicar o desfecho pela "resistência à mudança". Eliza Echternacht recordanos de maneira notavelmente sintética que a relação ao mundo de valores e o "agir em competência" são inseparáveis, "o agir competente é fundamentalmente determinado pelos valores que circulam através da 
actividade de trabalho". De onde surge uma nova abordagem da saúde no trabalho: o corpo em actividade, a sua hierarquização dos riscos, remetem ao agir em competência que não tem sentido sem a hierarquização de valores, que sustentam as normas de saúde desse corpo em actividade.

Dito de outro modo : se há um risco entre o nível macro de análise e a concepção da mobilidade das pessoas num espaço social, e o nível micro, incluindo o nível mesmo da actividade daqueles que prestam serviço, então, não se opera o que chamámos de dispositivos de dupla antecipação : o nível macro pode formalizar e antecipar os dados económicos, as necessidades de gestão do território concebidas na "desaderência" próprias à profissionalidade administrativa ou aos cálculos mercantis; mas ao nível micro da gestão quotidiana das prestações dos transportes pelos agentes de serviço, são antecipados por essas dimensões em valor da mobilidade das pessoas que transportam nesses territórios; dimensões que os profissionais da concepção têm interesse em "desencolher", se não pretendem conceber cegamente : "há de facto, ainda uma longa distância a percorrer para que sejam coerentes e contemporâneos os projectos de mobilidade e de desenvolvimento local" (Liliana Cunha).

Parece assim útil repensar de um ponto de vista ergológico este conceito de desenvolvimento : conceito ambíguo que transita das pertinências muito variáveis, das matemáticas à embriologia, da biologia à psicologia, da tecnologia à economia, da geoestratégia à ecologia. Em cada caso, a resposta é imposta : desenvolvimento em que direcção $\left.{ }^{20}\right]$ ? Nos diferentes campos disciplinares referidos, cada um pode antecipar, em graus variáveis, os fundamentos "científicos" das respostas. Qualquer vontade exógena de ajuda à inovação, de ajuda ao desenvolvimento, que não coloca em debate as diversas possibilidades, simultaneamente presentes em todas as situações de vida e de trabalho, acaba por esterilizar os saberes, as potencialidades, as reservas de alternativas.

Não se trata de validar o estado das coisas existente, como se as situações de vida não devessem ser transformadas graças aos recursos técnicos, científicos, médicos, da modernidade. Mas as políticas de desenvolvimento são votadas a uma certa ineficácia, até deslocam crises se não dão mais visibilidade aos saberes, às normas, às competências, às opções alternativas criadas no caldeirão das actividades produtivas locais e actuais. Não podemos pensar a actividade humana em "desaderência", à distância dos debates de normas, das dificuldades que ela deve tratar dia após dia. Neste ponto, cremos que existe uma competência ergológica, para trabalhar nesta maior visibilidade, mesmo se nunca pensamos que isto fosse tarefa fácil.

\section{Considerações finais}

Finalmente, a competência ergológica sobre as questões do desenvolvimento funda-se no encontro e na elaboração progressiva do conceito de actividade humana. Se este se estrutura em sucessão, encadeamento, em experiência acumulada de debates de normas, então, a actividade está sempre a procurar a sua maneira de viver a sua saúde ; ela tem que fazêlo numa confrontação sempre problemática entre as normas antecedentes de várias ordens e dos encontros do meio natural, humano, social, incluindo o encontro de um "si-mesmo", nunca realmente estandardizáveis, previsíveis, avaliáveis. 

num plano já não epistemológico, mas axiológico. Em termos jurídicos recordemos que a exterritorialidade dispensa os diplomatas acreditados num país estrangeiro, do respeito da jurisdição do Estado onde se encontram. Eles exercem num território, mas sem ser objecto das suas normas e, assim, dos valores que as sustentam. Existe efectivamente um equivalente axiológico do pólo da "desaderência", para o qual reenvia o que em nós há de universalizante no assumir dos nossos valores (do "bem comum"). Mas a postura da "exterritorialidade" começa então quando pretendemos dispor de uma versão estabilizada desses valores, de uma capacidade de hierarquizálos, de os declinar, ou integrá-los numa "ciência", da mesma forma que o fazem as modelizações conceptuais produzidas no pólo da "desaderência". E pensamos então poder impor avaliações, direcções "boas" de desenvolvimento, ou interpretar o "sistema de valores" dos outros, sem se sentir constrangido a aprender a partir das experiências reais de vida, como as actividades humanas se debatem com os valores. 0 equivalente do facto de lembrar o pólo da "aderência" seria aqui a consideração do "retrabalho" indefinido neste mundo de valores, através da prova dos debates de normas da actividade.

Não desenvolveremos aqui o jogo muito complicado desta dualidade do axiológicoepistemológico, duas dimensões indissociáveis no destino humano, mas que acabam por ter relações muito diferentes com a sistematicidade, com o vai-evem entre aderência e 
desaderência, com a visibilidade, com as relações de poder. A sua articulação é incontornável para construir o viver em conjunto, mesmo se essas duas dimensões poderiam defrontar-se uma contra a outra? [22]. Contentar-nos-emos com o seguinte : um desenvolvimento local concebido unicamente na desaderência ignora os recursos, os saberes gerados através das renormalizações das pessoas ou dos povos em jogo (os recursos do pólo 2 do dispositivo dinâmico a três pólos). Ora, esta atitude epistemológica aparece-nos quase sempre relacionada com esta postura axiológica, que acabamos de qualificar por exterritorialidade: prescrever o desenvolvimento de entidades humanas a partir das opções normativas, ignorando aquelas que as entidades construíram através da acumulação das suas renormalizações industriosas. 0 que nos ensina o encontro da actividade é que nenhuma postura de exterritorialidade [23], consegue ser verdadeiramente eficaz ou aceitável, se não houver preocupação em considerar os valores que atravessam o território (incluindo o sentido próprio referido por Liliana Cunha).

Cremos que se encontra aqui a convergência que reúne sobre bases da experiência e de competências diversas dos parceiros deste dossier. Acabamos de mencionar a crítica de exterritorialidade emitida por Liliana Cunha. Também é verdade para o programa de investigação de Abderhamane Fyad, que chama atenção para uma aprendizagem das dinâmicas endógenas do trabalho informal, ao recusar uma postura de descrição e avaliação pré-formatada do ponto de vista do trabalho stricto sensu. Eliza Echternacht defende uma ruptura em matéria de gestão da saúde, que aliás não pode ser vista somente como assunto de especialistas, em exterioridade, em relação às confrontações normativas, que desenvolvem os colectivos humanos e de onde resulta uma certa gestão da saúde. Marianne Lacomblez não diz outra coisa quando ela se distancia relativamente aos peritos que elaboram os índices do INDISA : obra positiva para promover a igualdade de sexos em África, mas que pressupõe um "carácter consensual dos seus valores subjacentes", uma alternativa "predefinida" e não "ancorada no conhecimento das actividades humanas". Enfim, corresponde à substância dos trabalhos de Abdallah Nouroudine, que refere neste dossier, insistindo ainda sobre o facto de que ignorar o envolvimento dos povos nas actividades industriosas acaba provavelmente por ser o melhor meio para passar ao lado da relação entre o seu mundo de competências investidas e os valores da vida capazes de animar uma nova fase do seu desenvolvimento : "como tornar o desenvolvimento mais apropriado para os povos e adaptado às realidades locais? Respondemos propondo que o desenvolvimento só pode ser apropriado pelos povos e adaptado às realidades locais se for concebido $\mathrm{e}$ concretizado a partir das actividades humanas, em geral, e do trabalho, em particular". O esquecimento do trabalho, acrescenta ele, "é a tradução de uma abordagem do desenvolvimento que perde a carruagem", postura típica, diríamos nós, de exterritorialidade ${ }^{[24}$.

Resta uma ou duas questões extremamente delicadas que nos contentaremos de assinalar :

Como constituir dispositivos pertinentes para introduzir nas questões do desenvolvimento o necessário diálogo do pólo dos conhecimentos produzidos na desaderência e do pólo dos saberes gerados nos debates de normas em aderência? Diálogo levantado pelo pólo de universalidade dos valores e do seu tratamento através da procura sempre resingularizada do que pode valer aqui e agora como saúde. Com esta perspectiva, Abdallah Nouroudine (2006), fala de grupos de encontro de 
desenvolvimento, à semelhança do que a démarche ergológica procura quando coloca em prática no mundo do trabalho os "Groupes de rencontres du travail". Ora, deparámo-nos com uma dificuldade já evocada a respeito dos níveis de intervenção pertinentes : não podemos privilegiar nem programar a priori os pontos de ancoragem ou de cristalização colectivas pertinentes para mostrar as suas reservas de alternativas. Eliza Echternacht insiste sobre a dimensão colectiva de toda a abordagem da saúde no local de trabalho. No entanto, ela questiona como podemos aceder às "configurações colectivas", que permitem compreender esta "génese de processos colectivos de adoecimento" ? De facto, ela retoma a ideia que as configurações colectivas não são prédeterminadas : como sempre no que diz respeito a toda a actividade humana, elas devem ser em parte localmente descobertas. A sua experiência de intervenção em empresas conduziu-a nesse sentido a utilizar o conceito ergológico de entidades colectivas relativamente pertinentes (ECRP). Mas então, como identificar as ECRP, relativamente mais pertinentes que outras, capazes de servir de matrizes para os Grupos de Encontro de Desenvolvimento (aldeias, comunidades, irmandades, tipos de actividade industriosas, grupos projectos de desenvolvimento, grupos colaborativos em torno de uma ONG... etc.) ? Questão essencial e delicada a propor no seguimento dos trabalhos que irão enquadrar-se nessas perspectivas.

Enfim, como já o lembramos, em relação a questões como a do "desenvolvimento sustentável", actualmente levantam-se verdadeiros problemas críticos para os quais a humanidade tem que se pensar como um todo: aquecimento climático, esgotamento dos recursos naturais (solos) e fósseis, crise alimentar, deslocamento das zonas de crescimento demográfico e industrial com diversas necessidades novas a satisfazer.

Portanto, de acordo com os processos socráticos num duplo sentido, próprios aos dispositivos dinâmicos a três pólos, de que os Grupos de Encontro de Desenvolvimento poderiam constituir uma concretização alargada, a visão universalista e as reservas de alternativas locais teriam de dialogar em condições de urgência e segundo horizontes novos. As competências ("para viver") trazidas pelas actividades humanas diversificadas (pela história das suas renormalizações colectivas) são capazes de indicar vias fecundas e originais para a orientação dos desenvolvimentos [1], bem como para os saberes globais (científicos, técnicos e planetários) e o reconhecimento da humanidade como um todo, tem que se pôr à prova e caminhar ao longo desses diálogos.

De um lado e do outro, a postura de desconforto intelectual (uma dimensão essencial do $3^{\circ}$ pólo dos DD3P), é a condição para abandonar tanto a postura reificada e mortífera de exterritorialidade como a defesa agressiva, ou em certos casos obscurantista, dos particularismos e comunitarismos.

Não podemos pensar "o" desenvolvimento no planeta, sem tomar em consideração as enormes desigualdades entre as aglomerações humanas, e ao mesmo tempo, sem ter em conta a extrema diversidade dos patrimónios humanos, cuja visibilidade e valorização são indispensáveis para uma política de desenvolvimento, que pretende não ser uma simples recondução das relaç̃oes de força existentes. Simultaneamente, deve progredir na consciência dos grupos humanos a ideia de que a humanidade é uma. "Conceber o desenvolvimento" nunca pode antecipar "trabalhar o desenvolvimento".

Verdadeiro desafio, ele o é : mas podemos fazer de outra forma? 


\section{BIBLIOGRAFIA}

Conte, B. (2005). Le concept de développement. Retirado em Junho, 18, 2005, de http://conte.ubordeaux4.fr

Doumbia, F. (2007). Travail et identité en Afrique noire. Thèse de Doctorat en Philosophie, Université de Provence, Aix en Provence.

Latouche, S. (2001). Le développement, histoire d'une croyance occidentale. Presses de l'Institut des Sciences Politiques.

Legouté, J.R. (2001). Définir le développement : historique et dimensions d'un concept plurivoque. Cahier de recherche du Groupe de recherche sur l'intégration continentale, Université du Québec, Volume 1, 1, 1-43. Manvoutouka, T. (2008). Une introduction critique au concept de développement. Mémoire Master 2, LEA, Université de Provence.

Nouroudine, A. (2001). Techniques et cultures, comment s'approprie-ton des technologies transférées? Toulouse : Octarès Editions.

Nouroudine, A. (2003). Travail et mobilisation de la main d'œuvre, éléments d'analyse épistémologique. In Sandrine Michel \& Xavier Oudin. La mobilisation de la main d'œuvre. Éditions : L'Harmattan.

Nouroudine, A. (2006, novembre). La recherche universitaire aux Como-

res, entre enjeux théoriques et enjeux pratiques. Communication présentée au Colloque UNESCO. France : Paris.

Rostow, W.W. (1960). Les étapes de le croissance économique. Paris : Éditions le Seuil.

Schwartz Y. \& Durrive L. (2003). Travail et Ergologie. Entretiens sur l'activité humaine. Éditions :Octarès.

Schwartz, Y. (2007). Un bref aperçu de l'histoire culturelle du concept d'activité. @ctivités, 4, 2, 122-133.

Schwartz, Y. (2007). Produire des savoirs entre adhérence et desadhéren-

ce in Marianne Cerf et Pascal Béguin (Dir.), Dynamique des savoirs, dynamique des changements. Editions : Octarès. (à paraitre).

Schwartz, Y. (2008). Les deux paradoxes d'Alain Wisner. In Philippe Geslin,

Réfl xions sur l'Anthropotechnologie. Paris, Editions : INRA. (no prelo). Sibelet, N. (1995).

L'innovation en milieu paysan, ou la capacité des ac-

teurs locaux à innover en présence d'intervenants extérieurs, Thèse de Doctorat, Institut National de la Recherche Agronomique. Paris.

Sindzingre, A. (2006-2007). Théories du développement. Chroniques dans Le Monde Economique.

Treillet, S. (2002). L'économie du développement. Problèmes Economiques (dossier Afrique : Les chemins de la croissance), 2906, 1-43.

Wisner, A. (1997). Anthropotechnologie : vers un monde industriel polycentrique. Toulouse : Éditions Octarès. 


\section{NOTAS}

1. Alain Wisner - foi membro do júri da nossa tese (em 1986) e da tese de Abdallah Nouroudine (1997), tendo produzido o prefácio da sua obra publicada em 2001. Ele dirigiu o Laboratoire du Conservatoire National des Arts et Métiers, com que coopera já há muito tempo com o Departamento de Ergologia da Université de Provence e com o Departamento de Psicologia do Trabalho da Faculdade de Psicologia e de Ciências da Educação da Universidade do Porto. A Ergonomia da actividade; em questão, é particularmente presente no Departamento de Engenharia de Produção de Belo Horizonte, onde Eliza Echternacht trabalha. Abderhamane Fyad criou o Diploma de Formação em segurança no trabalho, para a concepção do qual contou com a colaboração de "ergólogos", mas também de ergónomos dessa escola. Quanto a Rufino Adriano, foi na sequência de uma aula sobre Alain Wisner e sua antropotecnologia, no Departamento de Ergologia, na Université de Provence em 2005, que foram encetados contactos que culminaram com a criação de um Centro de Investigação sobre Ergologia e Desenvolvimento, em Moçambique, sob sua responsabilidade.

2. Nomeadamente, pelo intermédio do ergónomo Jacques Duraffourg, antigo membro do Laboratório de Alain Wisner e co-fundador desde a sua origem da démarche ergológica.

3. Cf. Schwartz Y. \& Durrive L. (2003). Travail et ergologie. Entretiens sur l'activité humaine. (p. 260 e seguintes). Ver igualmente o glossário em anexo.

4. De acordo com um relatório do B.I.T. de 2003, 93\% dos empregos não agrícolas no Benin são de actividade informal.

5. Uma tese de uma Costa Marfinense, recentemente apresentada ao Departamento de Ergologia, inscreve-se contra esta determinação da noção de "trabalho informal" definida no negativo (ver F. Doumbia, 2007).

6. Acrescentamos que a rede de convergências e de intercâmbios entre os colegas brasileiros e os protagonistas de uma démarche como a ergologia parece-nos inscrever-se nos traços próprios à história política, social e cultural do Brasil. A herança de Paulo Freire nos diversos movimentos de educação popular, as sinergias tecidas durante o período da ditadura militar, num país marcado por grandes desigualdades económicas e sociais, favoreceram nas universidades e nos movimentos sociais uma extrema atenção aos saberes e valores da vida social das minorias, dos "excluídos", dos habitantes das favelas. No quadro das dinâmicas que relacionam "movimentos sociais" e grupos universitários, esta herança militou, para uma presença a definir, desses patrimónios de saber e de valores nas instituições científicas e culturais, já que se tinha identificado a operatividade essencial, embora na penumbra da vida social deste país imenso. Além disso, em relação a outros países marcados por antigas tradições universitárias, o Brasil sofre menos o peso da cultura (mesmo se existe também e tende a aumentar) no que concerne à aceitação de cooperações transdisciplinares. Sobre esses pontos, ver em Schwartz, Y. \& Durrive, L. (s/d). Le dialogue 5. In Yves Schwartz \& Louis Durrive (Dir.). L'activité en dialogues. Éditions Octarès. (no prelo).

7. Tendencialmente porque não se trata de essencialismo feminista, como refuta Marianne Lacomblez, e que as situações e histórias podem diversamente actualizar e ponderar este tipo de reservas de alternativas.

8. Ver Mohamed Yunus, Prémio Nobel da Paz em 2006, e a sua entrevista ao Le Monde 2, de 26 de Abril de 2008.

9. A reflexão de Abdallah Nouroudine sobre o lugar da universidade na sociedade comoriana tem do nosso ponto de vista um valor mais geral: "se o método da participação corresponde a uma tentativa de resposta ao problema da inadaptação ou da inadequação entre um projecto e uma realidade", do que é que se trata quando falamos da universidade? Neste caso, responde ele, a participação como resposta a um problema de inadequação entre um projecto e uma realidade acaba por ser um problema epistemológico, político e ético que devemos examinar em dois 
planos: o do enraizamento da instituição universitária na sociedade, por um lado, e o da adequação entre a investigação, os projectos de desenvolvimentos e as necessidades reais, por outro lado. Esta "orientação", que deveria permitir produzir vários tipos de saberes específicos aos Comores e próprios para conceber um desenvolvimento ajustado, supõe que "a investigação não seja nem uma ilha isolada do resto do mundo, nem um sector estanque separado das outras dimensões e actividades da vida social". o que supõe, acrescenta ele, tanto de humildade como de curiosidade, de rigor e de audácia (Nouroudine, 2006).

10. É fácil avaliar este fenómeno pela internet. Podemos assinalar, por exemplo, Rostow (1960); Legouté (2001); Treillat (2002); Conte (2005). Um Master Ethique et Développement durable, organizado em Lyon III, dirigido pelo Professor J-J Wunenburger, propõe uma bibliografia consequente no site seguinte: http://fac- dephilo.univ-lyon3.fr/5003040IL/0/ fiche_03_formation/\&RH=PHI-FORM-master

11. Neste caso concreto, colhemos uma quantidade importante de informações sobre África, na Revista Problèmes Economiques, assim como na crónica "Théorie du Développement" no Le Monde Economie 2006-2007, por Alice Sindzingre.

12. Os "Elefantes Brancos", de acordo com o termo que parece consagrado. Consultar a excelente Monografia de Mestrado de LEA, elaborada sob direcção de R. di Ruzza, de Manvoutouka, T. (2008). Une introduction critique au concept de Développement. Thèse de Master. Université de Provence, Aix en Provence.

13. O Doutor Benzerroug El Hadi, responsável da OMS em Maputo, evocou diversas formas de ajuda dos países doadores, cada uma com as suas vantagens e desvantagens.

14. Alguns falam hoje, a propósito de países ricos graças aos seus recursos petrolíferos ou em gazes, de um "crescimento" (medido com parâmetros meramente quantitativos) "sem desenvolvimento" (esta noção conduzindo ao uso de indicadores mais largos, e que supostamente medem o futuro das populações em função de diferentes critérios mais qualitativos).

15. Ver os exemplos dos trabalhos de Latouche (2001).

16. Evocaremos o património da antropologia wisneriana. Consultar igualmente Manvoutouka, $\mathrm{T}$. (2008), p.42: « les survivances ne sont pas nécessairement des techniques arriérées ».

17. Consultar a tese de Nouroudine (2001) sobre a "modernização" da pesca nos Comores, capítulo 4.

18. Ver Schwartz, Y. \& Durrive, L. (2003) e Schwartz, Y. (2007).

19. Cf Doumbia, F. (2007); Manvoutouka, T. (2008), p.22: “a pobreza não remete tanto a indicadores em dinheiro, mas mais para uma ausência de suportes e laços familiares".

20. Durante um seminário na Faculté de Psychologie et de Sciences de l'Éducation de l'Université de Genève (11/06/08), avançamos a proposta de uma esquematização do teor do conceito de desenvolvimento, desde o seu uso na matemática, na embriologia, na psicologia da criança, na tecnologia e depois para o campo do desenvolvimento económico-social, segundo um duplo movimento inverso, evoluindo entre um e zero: na matemática, o "desenvolvimento" quando o termo aparece pode ter o valor 1 , já que a processualidade, etapa após etapa, acaba por ser estritamente definida e o princípio da progressão disponível. Trata-se de um valor que decresce progressivamente até ao campo económico-social à medida que crescem, pelo contrário, no seio do processo do que é designado "desenvolvimento", o que nós chamamos de debates de normas, e que proíbem toda a antecipação em desaderência do seguimento lógico da história.

21. O que Georges Canguilhem exprime de forma soberba no Le Normal et le Pathologique (1966, p.119): “o que é normal, para ser normativo em condições dadas, pode tornar-se patológico numa outra situação se se mantiver idêntico a si. Desta transformação é o indivíduo que é juiz porque é ele quem sofre, no momento em que se sente inferior às tarefas que a situação nova lhe propõe". 22. Porque, no texto de Marianne Lacomblez, a vigilância (das mulheres no meio de trabalho maioritariamente masculino) fica tanto tempo silenciosa? Porque é tão difícil dizer? 
23. Esta crítica da exterritorialidade está também no centro do trabalho de Manvoutouka, $\mathrm{T}$. (2008), pp. 6-7.

24. Por exemplo, as técnicas de irrigação económicas em água, de protecção dos recursos florestais, ou de solidariedade familiar ou comunitária. É nestes casos que a experiência das instituições que trabalham há muito tempo no terreno é preciosa e indispensável.

\section{AUTORES}

\section{YVES SCHWARTZ}

Université de Provence, Département d'Ergologie-Analyse Pluridisciplinaire des Situations de travail, 29 Avenue R.Schumann, 13 100, Aix-en-Provence Cedex, France yves.schwartz@univ-provence.fr

\section{RUFI ADRIANO}

Universidade São Tomás de Maputo, Av. Ahmed Sekou Torré 610 Maputo Moçambique rufinoadriano@yahoo.fr

\section{FYAD ABDERRAHMANE}

Faculté de médecine d'Oran - Université d'Oran Service de médecine du travail - EHU Oran abfyad@yahoo.fr 